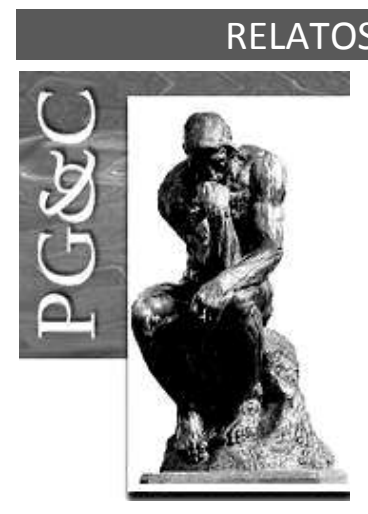

\title{
MECANISMOS PARA O COMPARTILHAMENTO DE CONHECIMENTO CIENTÍFICO COM A SOCIEDADE
}

\author{
Rayse Kiane de Souza \\ Mestre em Engenharia e Gestão do Conhecimento pela Universidade \\ Federal de Santa Catarina, Brasil. \\ E-mail: raysekiane@gmail.com \\ Márcio Vieira de Souza \\ Doutor em Engenharia de Produção pela Universidade Federal de Santa \\ Catarina, Brasil. Professor da Universidade Federal de Santa Catarina, \\ Brasil. \\ E-mail: marciovieiradesouza@gmail.com \\ Clarissa Stefani Teixeira \\ Doutora em Engenharia de Produção pela Universidade Federal de Santa \\ Catarina, Brasil. Professora da Universidade Federal de Santa Catarina, \\ Brasil. \\ E-mail: clastefani@gmail.com
}

\section{Resumo}

Este trabalho objetiva discutir o papel das instituições de pesquisa e as tecnologias para o compartilhamento de conhecimento científico de instituições de pesquisa, universidades e grupos de pesquisa, com a sociedade. Assim, esta pesquisa pode ser classificada como exploratória bibliográfica e também documental. $O$ estudo demonstra importância dos grupos de pesquisa e das universidades se colocaram como disseminadores do conhecimento, ressaltando os seus papeis de desenvolvedores e decodificadores do saber. Desta forma, a tecnologia possui capacidades para mudar a forma como as instituições criam, organizam e divulgam seus conhecimentos. Para isto, o estudo identifica 16 métodos ou técnicas de gestão do conhecimento baseados em tecnologias da informação e comunicação, e mais de 40 ferramentas que podem cumprir e auxiliar o proposto por estes métodos. Sendo suas principais características a capacidade de interatividade e integração de diferentes públicos, recuperação de conhecimento e capacidade de dar visibilidade às instituições.

Palavras-chave: Compartilhamento de conhecimento. Conhecimento científico. Tecnologias da informação e comunicação. Instituições de pesquisa.

\section{MECHANISMS FOR SHARING SCIENTIFIC KNOWLEDGE WITH SOCIETY}

\begin{abstract}
This paper discuss the role of research institutions and technologies for sharing scientific knowledge from research institutions, universities and research groups, to society. Thus, this research can be classified as exploratory bibliographic and documentary. The study demonstrates the importance of research groups and universities to place themselves as disseminators of knowledge, highlighting their roles as developers and decoders of knowledge. In this way, technology has the capacity to change the way institutions create, organize and disseminate their knowledge. For this, the study identified 16 methods or techniques of knowledge management based on information and communication technologies, and more than 40 tools that can fulfill and assist the proposed by these methods. Their main characteristics are the ability to interact and integrate different audiences, recover knowledge and the ability to give visibility to institutions.
\end{abstract}

Keywords: Knowledge sharing. Scientific knowledge. Information and communication technologies. Research institutions.

Perspectivas em Gestão \& Conhecimento, João Pessoa, v. 10, n. 1, p. 131-151, jan./abr. 2020. DOI: http://dx.doi.org/10.21714/2236-417X2020v10n1p131

http://periodicos.ufpb.br/ojs2/index.php/pgc. ISSN: 2236-417X. Publicação sob Licença (cc) EY-NC-ND 


\section{INTRODUÇÃO}

Para Björk (2007) a velocidade do progresso na ciência sempre foi fortemente dependente de quão eficientemente os pesquisadores podem compartilhar seus resultados, tanto para seus pares, quanto para os indivíduos da sociedade dispostos a implementar esses resultados em novas tecnologias e práticas. O conhecimento gerado a partir das atividades de pesquisa deve ser gerenciado e compartilhado, enfatizando um aprendizado colaborativo e cooperativo em rede, como forma de incrementar o potencial de inteligência coletiva dos pesquisadores pertencentes aos grupos de pesquisa (FREITAS JUNIOR et al., 2017).

As universidades são as principais responsáveis por gerar e disseminar conhecimento, em grande parte, isso é devido aos grupos de pesquisa que desenvolvem estudos e contribuem para o avanço científico e tecnológico, gerando e armazenando grande quantidade de ativos de informação e conhecimento. Isto ocorre por meio de projetos de pesquisa, publicação de trabalhos científicos e tecnológicos e redes de pessoas (FREITAS JÚNIOR et al., 2017).

O Diretório de Grupos de Pesquisa (DGP) do Conselho Nacional de Desenvolvimento Científico e Tecnológico (CNPq), inventário dos grupos de pesquisa científica e tecnológica em atividade no país, apresenta as informações relativas aos recursos humanos constituintes dos grupos (pesquisadores, estudantes e técnicos), às linhas de pesquisa em andamento, às especialidades do conhecimento, aos setores de aplicação envolvidos, à produção científica, tecnológica e artística e às parcerias estabelecidas entre os grupos e as instituições, sobretudo com as empresas do setor produtivo (CNPQ, 2020). Porém, a produção científica, tecnológica e artística dos grupos é contabilizada em censos bienais e somente com os dados inclusos no currículo Lattes dos participantes. As produções científicas são armazenadas e compartilhadas pelos publicadores, revistas, periódicos, editoras, congressos, repositórios institucionais, entre outros. Cabe aos grupos de pesquisa interessados buscar meios para a divulgação e armazenamento de suas produções, para que o conhecimento não fique somente restrito aos seus pares na comunidade acadêmica.

Para Correa (2012) é por meio da publicação de artigos científicos que os pesquisadores compartilham informações para o desenvolvimento científico, tecnológico e social. Porém, com o processo de publicação e divulgação destes trabalhos é bastante restrito à comunidade científica, este meio acaba excluindo diversos interessados em suas descobertas. Os meios de publicações científicas como revistas, anais de congressos e periódicos mesmo sendo o meio formal e comumente utilizado pela comunidade científica, pode apresentar limitações para o compartilhamento de conhecimento até dentro da própria comunidade. Estas publicações possuem limitações de alcance que dependem de diversos fatores, como número de citações, fator de impacto e bases de dados que fazem a indexação destas publicações, sendo muitas destas publicações restritas a membros de instituições ou universidades ou ao pagamento de quantias significativas.

O contexto da sociedade atual, com grandes volumes de conhecimento e informação, e com o barateamento e a popularização de tecnologias da informação e comunicação (TIC), incentiva a democratização e o livre acesso ao conhecimento a toda sociedade (CORREA, 2012). As TIC podem ser aliadas para aprimorar a colaboração acadêmica em grupos de pesquisa, assim como fornecer um meio de comunicação do conhecimento científico com a sociedade. Assim, este artigo busca entender o papel das instituições de pesquisa em compartilhar o conhecimento científico com a sociedade. Assim como explorar quais ferramentas aliadas aos métodos e técnicas de gestão do conhecimento (GC) podem auxiliar este processo.

Perspectivas em Gestão \& Conhecimento, João Pessoa, v. 10, n. 1, p. 131-151, jan./abr. 2020. 


\section{FUNDAMENTAÇÃO TEÓRICA}

\subsection{Conhecimento Científico}

Para Oliveira et al. (2006), o conhecimento científico é o conhecimento resultante de atividades científicas, e seu objetivo é demonstrar, por argumentação, uma solução proposta para um problema, em relação a uma determinada questão. O conhecimento científico também pode ser subdividido em tácito e explícito. O conhecimento científico explicito é toda forma de conhecimento codificado, de fácil estruturação, que pode ser comunicado por sistemas estruturados ou meios formais, compreendendo a literatura científica. Já o conhecimento científico tácito não pode ser transmitido por meio de textos, fórmulas ou diagramas, mas, sim, pelo contato pessoal entre cientistas (LEITE; COSTA, 2007). Leite e Costa (2007) ainda ressaltam que o conhecimento científico tácito está altamente relacionado com a experiência e a competência do pesquisador.

O conhecimento científico é derivado da aplicação de métodos mais formais que visam aumentar o rigor em relação a diferentes posições sobre validade e confiabilidade (RAYMOND et al., 2010). A definição de conhecimento científico está ligada à análise dos dados utilizados e ao processo de construção do conhecimento, pois as atividades executadas em um domínio comercial são bem definidas, bem como o conhecimento necessário para a execução de cada uma dessas atividades, enquanto que as atividades científicas incluem sequências de tentativas, porque o domínio não é completamente conhecido (OLIVEIRA et al., 2006). Ou seja, o conhecimento científico é construído gradualmente e pode estar sujeito a alterações.

Para Raymond et al. (2010), a ciência se refere a qualquer conhecimento ou prática sistemática, origem do método científico que se concentra em princípios ou processos de estudo acordados, incluindo confiabilidade e validade, base do conhecimento científico. Para Leite e Costa (2007), a criação do conhecimento científico não se difere do proposto por Takeuchi e Nonaka (2008) para a criação do conhecimento. A partir da interação entre conhecimento científico explícito e conhecimento científico tácito, torna-se viável a criação de um novo conhecimento científico. Sendo o conhecimento tácito de difícil formalização, a comunicação é imprescindível no meio científico para a criação de novos conhecimentos (LEITE; COSTA, 2007).

Independente da complexidade e volume de informações tratadas ou do modo como é estruturado, a colaboração é fundamental para a construção do conhecimento científico (OLIVEIRA et al., 2006). Raymond et al. (2010) afirmam que mesmo o conhecimento científico, em sua grande maioria, apresentado de forma explícita, sempre será interpretado por indivíduos (incluindo pesquisadores), que utilizam seus conhecimentos prévios e suas orientações de pesquisador para isto. A colaboração e comunicação em ambientes científicos geralmente são restritas e ocorrem somente entre um pequeno número de pessoas que trabalham no mesmo grupo. Para Oliveira et al. (2006), muitos pesquisadores não conhecem outros pesquisadores que trabalham em pesquisas correlacionadas, devido à distância física ou à cultura da instituição ou dos pesquisadores. O uso de tecnologias para a gestão do conhecimento científico é uma maneira de melhorar a comunicação e interação entre pesquisadores e melhorar a qualidade de conhecimento produzido, assim como facilitar os processos de divulgação e decodificação do conhecimento científico para a sociedade (OLIVEIRA et al., 2006).

\subsection{Compartilhamento de Conhecimento}

O conhecimento pode ser compartilhado por meio de um processo de troca de experiências, é um processo importante no gerenciamento do conhecimento, melhora o

Perspectivas em Gestão \& Conhecimento, João Pessoa, v. 10, n. 1, p. 131-151, jan./abr. 2020. 
desempenho, economiza tempo e custos operacionais da organização. O compartilhamento de conhecimento incentiva os indivíduos a serem criativos e aumenta o nível de aplicação do conhecimento, especialmente no processo de ensino e aprendizagem (MUDA; YUSOF, 2015). Paulin e Suneson (2012) apontam que, tanto o termo compartilhamento quanto transferência, são utilizados para tratar do mesmo conceito, e que a literatura falha ao tentar distingui-los. Para Jonsson (2008), não há uma diferença, ambos os termos são usados dentro do quadro de referência, tanto o compartilhamento de conhecimento quanto a transferência de conhecimento são usados e discutidos de forma intercambiável.

O objetivo do compartilhamento de conhecimento é distribuir o conhecimento correto para as pessoas corretas no momento correto (RIVERA; RIVERA, 2016, p.24). Para Davenport e Prusak (1998), o compartilhamento de conhecimento exige confiança e deve ser estimulado e recompensado pela organização, sendo a tecnologia uma facilitadora deste comportamento organizacional. Conhecimentos diferentes são compartilhados de formas diferentes. 0 conhecimento explícito, que possui uma fácil codificação, é facilmente compartilhado por meio de documentos, formulários e manuais. Já o compartilhamento do conhecimento tácito precisa ser estimulado através da interação e comunicação entre os indivíduos (FULLWOOD; ROWLEY; DELBRIDGE, 2013).

O compartilhamento de conhecimento pode ocorrer tanto em nível individual quanto em nível organizacional. Em nível individual, o compartilhamento ocorre na troca direta entre indivíduos, em conversas e ajuda mútua. Já em nível organizacional, o compartilhamento é a captura, organização, reutilização e transferência de conhecimento baseado na experiência que reside dentro da própria organização (LIN, 2007).

Três aspectos chave podem ser identificados em um ambiente que favorece o compartilhamento de conhecimento, criando um contexto em que os processos de compartilhamento sejam estimulados e facilitados: cultura, estrutura e tecnologia (VAN DEN HOOFF; HUYSMAN, 2009; DI CHIARA; ALCARÁ; TOMAÉL, 2010).

- Cultura: estabelecimento de uma cultura amigável ao conhecimento, caracterizada por uma orientação positiva em relação ao conhecimento e à criatividade.

- Estrutura: estrutura organizacional que facilite o compartilhamento de conhecimento, que indique os responsáveis pelas atividades relacionadas ao conhecimento e que auxilie as interações.

- Tecnologia: infraestrutura técnica que inclui o uso de tecnologias de informação e comunicação para auxiliar na troca de conhecimento.

A tecnologia apresenta um papel fundamental no compartilhamento do conhecimento, porém só se torna efetiva quando utilizada pelos indivíduos e integrada a cultura organizacional (DAVENPORT; PRUSAK,1998). Para Fullwood, Rowley e Delbridge (2013), estratégias de compartilhamento de conhecimento precisam ser planejadas e executadas para se acomodarem dentro da cultura estabelecida pela organização e, quando a gerência é favorável ao compartilhamento, os indivíduos percebem que uma cultura é prevalente e, consequentemente, o exemplo fornecido pela administração pode ser altamente significativo.

A utilização de tecnologias de informação e comunicação nos processos de compartilhamento de conhecimento pode permitir pesquisas, acesso e recuperação rápida de conhecimento e oferecer suporte à comunicação e colaboração entre indivíduos da organização (LIN, 2007). As TIC podem influenciar positivamente o nível social da organização, reforçando o aspecto cultural do compartilhamento de conhecimento (VAN DEN HOOFF; HUYSMAN, 2009), tornando as atividades colaborativas mais eficazes, pois ajudam a superar as barreiras geográficas e temporais de comunicação (LIN, 2007).

Perspectivas em Gestão \& Conhecimento, João Pessoa, v. 10, n. 1, p. 131-151, jan./abr. 2020. 


\section{METODOLOGIA}

Este trabalho realiza uma pesquisa exploratória da literatura para identificar ferramentas que podem auxiliar o processo de compartilhamento de conhecimento gerado em instituições de pesquisa com a sociedade. Primeiramente é classificado como revisão exploratória da literatura, pois possui como finalidade desenvolver, esclarecer e modificar conceitos e ideias (GIL, 2008), a fim de desenvolver o conceito e elaborar hipóteses (MARCONI; LAKATOS, 2003). Quanto ao seu delineamento esta primeira etapa classifica-se como pesquisa bibliográfica, pois utiliza artigos e livros para a construção de fundamentação teórica e levantamento de dados iniciais, sobre compartilhamento de conhecimento e instituições de pesquisa, assim como os métodos de gestão do conhecimento que podem auxiliar este processo. A Figura 1 detalha as etapas de pesquisa:

Figura 1 - Etapas da pesquisa

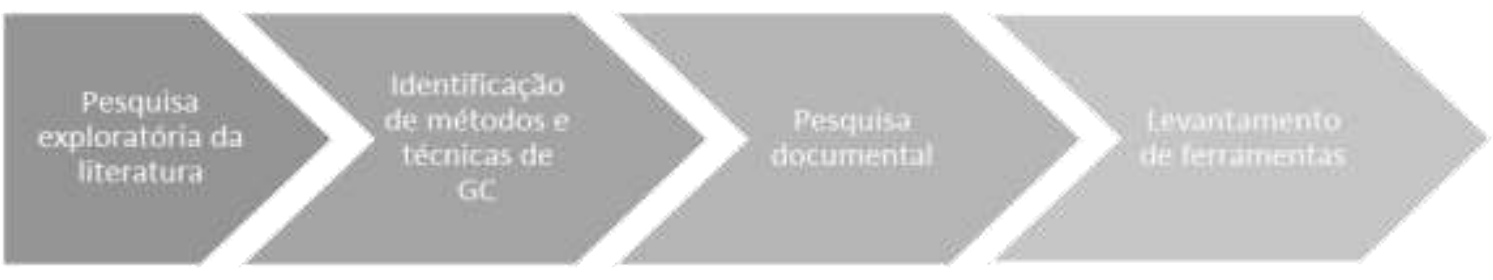

Fonte: Elaborado pelos autores

Duas bases de dados multidisciplinares foram selecionadas para a realização da pesquisa exploratória, Scopus com mais de 190 mil referências indexadas, incluindo artigos, artigos de eventos e anais, revisões, livros e capítulos de livros (SCOPUS, 2019) e Web of Science com 33 mil revistas acadêmicas (WEB OF SCIENCE, 2019). Com o objetivo de apresentar uma visão mais próxima da realidade das instituições de pesquisa brasileiras, uma terceira base foi incluída. Assim, também foi realizada uma busca no Portal de Periódicos da Coordenação de Aperfeiçoamento de Pessoal de Nível Superior (CAPES). Nas três bases foram pesquisados os termos gestão do conhecimento, tecnologia e informação e universidades.

Três critérios de seleção foram utilizados para definir a seleção dos artigos resultantes das buscas:

- Os artigos deveriam apresentar em seus títulos e resumos termos relacionando a TIC, gestão do conhecimento, comunicação científica, universidades, instituições de ensino superior, instituições de pesquisa ou grupos de pesquisa.

- O mínimo de duas de suas palavras-chave deveria ser condizente com os termos: conhecimento, gestão do conhecimento, compartilhamento ou disseminação do conhecimento, técnicas ou tecnologias de gestão do conhecimento, técnicas ou tecnologias de compartilhamento ou disseminação do conhecimento, universidade, grupos de pesquisa, instituição de ensino superior, comunicação científica.

- Acesso gratuito para leitura por meio do Portal da CAPES, Google, Google Acadêmico ou Research Gate nos perfis dos autores. Todos estes portais foram utilizados com acesso via VPN (Virtual Private Network) da Universidade Federal de Santa Catarina, onde é possível o acesso a diversas bases de dados e periódicos parceiros.

Nas buscas realizadas nas bases Scopus e Web of Science foram encontrados 279 e 100 artigos respectivamente, um total de 243 artigos únicos. A partir da aplicação dos critérios, 70 trabalhos foram considerados aptos. Os artigos foram lidos da íntegra e 15 destes utilizados na construção deste trabalho. Os artigos descartados não foram utilizados pois não apresentaram

Perspectivas em Gestão \& Conhecimento, João Pessoa, v. 10, n. 1, p. 131-151, jan./abr. 2020. 
fundamentação teórica ou resultados pertinentes aos tópicos que buscavam ser esclarecidos, como o papel da universidade no compartilhamento de conhecimento científico, e tecnologias para o compartilhamento de conhecimento, ou não apresentavam a tecnologia como foco de seus estudos de gestão do conhecimento.

A busca realizada no Portal de Periódicos da Capes resultou em mais de cinco mil resultados, assim optou-se por selecionar os mais relevantes segundo o portal. A relevância é definida pelo portal como o conjunto de visualizações e citações que 0 artigo possui. As 4 primeiras páginas de artigos mais relevantes, um total de 40 artigos, foram analisados utilizando os mesmos critérios de seleção das demais bases. Assim, 6 destes trabalhos foram utilizados. Outras referências, como livros, artigos e manuais, resultantes de buscas não sistematizadas no Google Scholar e Scielo também foram utilizadas.

$\mathrm{Na}$ segunda etapa da pesquisa foi realizada uma pesquisa documental para o levantamento de ferramentas disponíveis no mercado que cumprissem o proposto pelos métodos identificados. $\mathrm{O}$ foco foi selecionar ferramentas simples e populares que pudessem ser utilizadas por pessoas com diferentes níveis de habilidades. A partir do site institucional de cada ferramenta foram verificadas suas características e funcionalidades.

\section{COMPARTILHAMENTO DE CONHECIMENTO CIENTÍFICO COM A SOCIEDADE}

\subsection{O papel das instituições de pesquisa}

Na configuração socioeconômica do século XXI o conhecimento se transformou em um dos principais fatores de produção, no elemento fundamental para a produção de riquezas (MACHADO, 2001). A universidade emprega um papel milenar de criação, gestão e preservação deste conhecimento. Da necessidade do homem de entender a natureza para o desenvolvimento humano, para a necessidade de se fazer ciência, as instituições foram criadas e organizadas com o objetivo principal de produzir ciência e traduzir seus resultados para a prática (GOERGEN, 1998).

Para Wanderley (2017) a universidade é uma instituição social, um lugar, privilegiado para conhecer a cultura universal e as várias ciências, para criar e divulgar o saber, que forma de maneira sistemática e organizada os profissionais, técnicos e intelectuais de nível superior de que a sociedade necessita. A universidade moderna fundou-se na ideia de um conhecimento guiado por sua própria lógica, por necessidades intrínsecas a ele, tanto do ponto de vista de sua invenção ou descoberta como de sua transmissão (CHAUÍ, 2003). Von Zuben (1995, p.10) afirma que a universidade também pode ser vista como "uma coletividade, um grupo de indivíduos que, com suas capacidades, talentos e interesses dedicam-se a criação, ao avanço e propagação do saber". Para Santos e Almeida Filho (2008) só há universidade quando há graduação e pós-graduação, pesquisa e extensão.

As transformações socioeconômicas que levaram a configuração atual da sociedade do conhecimento também exerceram fortes transformações nas universidades, principalmente no excesso de informações e na decodificação do saber. Goergen (1998) ressalta que, em pouco menos de quatro séculos, toda a informação contida por uma universidade passou de pouco mais de 200 obras literárias, para quase incalculáveis quantidades de informações em repositórios físicos e digitais. Especificamente no que se refere ao conhecimento, nas últimas décadas as facilidades para seu armazenamento, em produção de livros ou softwares como instrumentos de socialização e de facilitação, se multiplicaram. Porém a concentração do poder de distribuição destes conhecimentos se manteve com instituições e organizações com o poder de gerar estas tecnologias (MACHADO, 2001). Devido à grande massa de conhecimento disponível, a decodificação deste se restringe cada vez mais a somente

Perspectivas em Gestão \& Conhecimento, João Pessoa, v. 10, n. 1, p. 131-151, jan./abr. 2020. 
especialistas, tornando as áreas de saber cada vez mais delimitadas, técnicas, codificadas e, por isso, sempre mais inacessíveis aos não-especialistas (GOERGEN, 1998).

Santos e Almeida Filho (2008) afirmam que, desde o fim do século XX, a universidade vem sofrendo alterações nas suas relações com a sociedade, passando de uma construção de conhecimento unilateral para um conhecimento mais interativo com a sociedade, potencializado pelas TIC. Estas mudanças proporcionam uma relação entre a ciência e tecnologia mais intensa, que exige uma maior participação da sociedade na produção e avaliação do conhecimento gerado.

Goergen (1998) ainda ressalta a necessidade de haver mecanismos e papeis de decodificadores destes conhecimentos dentro da universidade para um conhecimento democrático.

\begin{abstract}
A pesquisa científica dentro da universidade desempenha papel importante não só na produção de novos conhecimentos, mas também na sua capacidade de tornar acessíveis aos seus estudantes os avanços contínuos do saber. Assim, o cientista moderno deve ser também um decodificador, e a importância da universidade cresce à medida que aumenta a sua capacidade de decodificar e abranger um número crescente de especialistas nas diversas áreas do saber (MEIS; LETA;1996, p. 33).
\end{abstract}

Logo, a produção do conhecimento nas universidades tem o compromisso de formar profissionais para a sociedade por meio de uma proposta acadêmica voltada para o conhecimento que busca o aprendizado contínuo (AGUIAR FILHO; NASSIF, 2016). Nesse sentido, as universidades desempenham um papel essencial no processo de transformação da sociedade, pois são instituições que prezam pelo o avanço do conhecimento que modifica e transforma a dinâmica socioeconômica (LOGREIRA; MUSA; ZAPATA, 2016).

Para Santos e Almeida Filho (2008) as universidades:

Têm que estar ao serviço destas duas ideias mestras - sociedade de informação e economia baseada no conhecimento - e para isso têm de ser elas próprias transformadas por dentro, por via das tecnologias da informação e da comunicação e dos novos tipos de gestão e de relação entre trabalhadores de conhecimento e entre estes e os utilizadores ou consumidores (SANTOS; ALMEIDA FILHO, 2008, p.30).

A universidade é uma fornecedora de conhecimento e exerce um papel de divulgação de ideias e conhecimentos dentro da comunidade, por meio de duas funções principais: educação e pesquisa (DAGLI; SILMAN; BIROL, 2009). Para Machado et al. (2017), as atividades de pesquisa dentro da universidade estão diretamente associadas à atuação dos grupos de pesquisa, que são formados por pesquisadores que objetivam desenvolvimento de pesquisas que contribuam para o avanço da ciência. A universidade como centro de pesquisa, é responsável pelo avanço em diversas áreas do conhecimento, como cientifico, tecnológico, filosófico, artístico, social e humano, e a transmissão deste conhecimento encontra-se frente ao dilema de o que e como transmitir, devido ao seu crescimento vertiginoso (VON ZUBEN, 1995).

Estes grupos de pesquisa produzem ativos de conhecimento por meio de projetos de pesquisa, publicação de trabalhos científicos e tecnológicos e redes de pessoas, sendo um fator de influência no sucesso destas atividades a capacidade de gerenciar sistematicamente o conhecimento (FREITAS JUNIOR et al., 2017). Os centros de pesquisa dentro das universidades precisam ser proativos na gestão de seus conhecimentos para obter vantagem competitiva, particularmente na geração e divulgação de novos conhecimentos (TAN; NOOR, 2013).

Perspectivas em Gestão \& Conhecimento, João Pessoa, v. 10, n. 1, p. 131-151, jan./abr. 2020. 
Dentro das universidades, centros intensivos de educação, é primordial incluir e integrar os alunos aos pesquisadores, para que possam tomar consciência da importância da pesquisa. Envolver o aluno em práticas de pesquisa significa torna-lo mais que um mero receptor de conhecimento, e construir um saber coletivo (VON ZUBEN, 1995).

Para Oliveira et al. (2006), embora as universidades e os centros de pesquisa sejam intensivos em conhecimento, sua organização descentralizada, a alta complexidade dos dados e informações científicas e os processos peculiares podem se tornar obstáculos para uma gestão mais eficiente do conhecimento científico. Outro problema destacado na gestão do conhecimento em universidades é a dificuldade de colaboração no ambiente científico, principalmente pela falta de conhecimento e simples acesso às competências dos pesquisadores (OLIVEIRA et al., 2006). Fullwood, Rowley e Delbridge (2013) apontam que a estrutura organizacional das instituições de ensino superior pode constituir uma barreira significativa para o compartilhamento de conhecimento, assim como barreiras físicas e psicológicas, como por exemplo o individualismo de pesquisadores.

Ao longo dos anos muitas mudanças aconteceram no cenário das universidades para melhorar o compartilhamento de conhecimento, principalmente tornando diversos serviços e processos digitais e online. Sobre estas mudanças:

Encontramo-nos numa nova fase da experiência humana. Em resumo, estamos vivendo numa sociedade envolta num processo de profundas transformações, orquestradas, sobretudo, pelos avanços na tecnologia de armazenamento e transmissão de informações. Esta nova realidade tem reflexos que mudam a sociedade, os indivíduos, as instituições e sua interação (GOERGEN, 1998, p.13).

No entanto, a tecnologia da informação deve levar a uma mudança mais primordial do que automatizar e acelerar os processos tradicionais. Assim, as capacidades da tecnologia da informação podem mudar fundamentalmente a forma como os cientistas trabalham, colaboram e, consequentemente, criam, organizam e divulgam seus conhecimentos (OLIVEIRA et al. 2006).

\subsection{Tecnologias para o compartilhamento de conhecimento}

A economia moderna exige que as atividades de compartilhamento de conhecimento sejam uma importante prática dentro das organizações, principalmente apoiada pelo uso das TIC. Isso porque as TIC podem reduzir as barreiras de espaço e tempo nas atividades de compartilhamento de conhecimento (MUDA; YUSOF, 2015). Para Eid e Nuhu (2011), a utilização de TIC para o compartilhamento de conhecimento torna a gestão do conhecimento efetiva, e a utilização destas tecnologias impacta na capacidade dos indivíduos em compartilhar conhecimento.

Entende-se por TIC instalações físicas e serviços que suportam o uso e o compartilhamento de informação e conhecimento em organizações, abrangendo cinco aspectos: hardware, software, rede e comunicações, bancos de dados e equipe de gerenciamento. A infraestrutura de TIC pode aumentar o compartilhamento de conhecimento, além de ajudar os indivíduos a criar, transferir e compartilhar conhecimento de maneira eficaz. No contexto do ensino superior, as TIC podem aumentar o interesse dos professores em compartilhar conhecimento (MUDA; YUSOF, 2015).

Desta forma, a tecnologia se mostra uma grande aliada para a massificação do compartilhamento, assim como na quebra das barreiras geográficas e temporais da interação entre indivíduos, facilitando o acesso e recuperação do conhecimento. As implementações de 
gestão do conhecimento exigem uma ampla gama de ferramentas que são utilizadas em momentos distintos do processo, desde a criação até o compartilhamento (DAVENPORT; PRUSAK, 1998).

A tecnologia é usada para facilitar principalmente a comunicação, colaboração e o gerenciamento de conteúdo para uma melhor captura, compartilhamento, disseminação e aplicação do conhecimento (DALKIR, 2013). A mais valiosa função da tecnologia na gestão e compartilhamento do conhecimento é estender o alcance e aumentar a velocidade da transferência do conhecimento. A tecnologia da informação possibilita que o conhecimento de uma pessoa ou de um grupo seja extraído, estruturado e utilizado por outros membros da organização e por seus parceiros no mundo todo (DAVENPORT; PRUSAK, 1998). Porém, nem todas as técnicas ou métodos de gestão do conhecimento são baseados em tecnologias ou dependente delas, como mostra Young (2010), que divide as técnicas e métodos em baseados em TIC e não baseados em TIC.

A partir das proposições de Servin e De Brun (2005), Young (2010), e do mapeamento realizado por Orofino (2011), o quadro 1 apresenta os métodos e técnicas de gestão do conhecimento baseados em TIC para o compartilhamento de conhecimento. Após a seleção dos métodos e técnicas baseados em TIC na literatura, foram identificados, a partir da sua caracterização e exemplos fornecidos pelos autores, ferramentas que dão suporte a estes métodos e técnicas, complementadas por ferramentas específicas do ambiente de pesquisa nas universidades. As ferramentas identificadas são TIC que já estão prontas e disponíveis no mercado e não feitas sob demanda para suprir uma necessidade, mesmo havendo esta possibilidade para todos os métodos e técnicas.

Quadro 1 - Métodos e ferramentas de GC.

\begin{tabular}{|c|c|c|}
\hline $\begin{array}{c}\text { Métodos e técnicas } \\
\text { de GC }\end{array}$ & Descrição & Ferramentas \\
\hline $\begin{array}{l}\text { Comunidades } \\
\text { virtuais de } \\
\text { execução de } \\
\text { projetos }\end{array}$ & $\begin{array}{l}\text { Espaço de trabalho virtual colaborativo que permite } \\
\text { que as pessoas trabalhem juntas, } \\
\text { independentemente de onde estão localizadas } \\
\text { fisicamente. Envolve compartilhamento de } \\
\text { documentos, edição colaborativa e conferências de } \\
\text { áudio/vídeo, podendo ser um único software ou } \\
\text { uma combinação de ferramentas (YOUNG, 2010). }\end{array}$ & $\begin{array}{l}\text { Google Drive, } \\
\text { Microsoft Onedrive }\end{array}$ \\
\hline E-Learning & $\begin{array}{l}\text { Tecnologias da informação que oferecem } \\
\text { aprendizagem e treinamento para pessoas em suas } \\
\text { áreas de trabalho, favorecendo a reunião de } \\
\text { diferentes pessoas em locais distintos (SERVIN; DE } \\
\text { BRUN, 2005; OROFINO, 2010). }\end{array}$ & $\begin{array}{l}\text { Moodle, Google Sala } \\
\text { de Aula, Blackboard }\end{array}$ \\
\hline $\begin{array}{l}\text { Fóruns de } \\
\text { discussão }\end{array}$ & $\begin{array}{l}\text { Espaço digital que proporciona um "local de } \\
\text { encontro informal" para a troca de conhecimentos. } \\
\text { Permite às pessoas trabalharem em equipe, através } \\
\text { de uma rede, independentemente do local ou do } \\
\text { tempo (SERVIN; DE BRUN, 2005; OROFINO, 2010). }\end{array}$ & $\begin{array}{l}\text { Google Groups, fórum } \\
\text { de ambiente virtual de } \\
\text { aprendizagem, grupos } \\
\text { de Facebook, } \\
\text { WhatsApp, Reddit }\end{array}$ \\
\hline $\begin{array}{l}\text { Gerenciamento } \\
\text { de conteúdo }\end{array}$ & $\begin{array}{l}\text { Recurso para operacionalizar eficazmente as } \\
\text { estratégias colaborativas visando à eficiência da } \\
\text { cadeia de valor via web site ou portal (YOUNG, } \\
\text { 2010). }\end{array}$ & $\begin{array}{l}\text { Google Drive, } \\
\text { Microsoft Onedrive, } \\
\text { Site Wordpress }\end{array}$ \\
\hline $\begin{array}{l}\text { Páginas brancas, } \\
\text { páginas amarelas, ou } \\
\text { banco de } \\
\text { competências }\end{array}$ & $\begin{array}{l}\text { Recurso normalmente disponibilizado online que } \\
\text { permite que as pessoas encontrem colegas com } \\
\text { competências e conhecimentos específicos } \\
\text { (SERVIN; DE BRUN, 2005; ORIFINO, 2010). }\end{array}$ & $\begin{array}{l}\text { Lattes, Linkedin, } \\
\text { ResearchGate }\end{array}$ \\
\hline
\end{tabular}

Perspectivas em Gestão \& Conhecimento, João Pessoa, v. 10, n. 1, p. 131-151, jan./abr. 2020. 


\begin{tabular}{|c|c|c|}
\hline Blog & $\begin{array}{l}\text { Site que contém uma lista de artigos ou histórias } \\
\text { curtas, muitas vezes relacionadas a eventos atuais, } \\
\text { também podem ser fotografias, vídeos, gravações } \\
\text { de áudio ou uma mistura de todos os tipos } \\
\text { (YOUNG, 2010). }\end{array}$ & $\begin{array}{l}\text { Wordpress, Wix, } \\
\text { Joomla, Blogspot, blog } \\
\text { sem construtor }\end{array}$ \\
\hline Chat & $\begin{array}{l}\text { Ferramenta para troca de mensagens instantâneas } \\
\text { via web, em tempo real (YOUNG, 2010; OROFINO, } \\
\text { 2010). }\end{array}$ & $\begin{array}{l}\text { WhatsApp, } \\
\text { Messenger, Hangouts, } \\
\text { Telegram, Slack, } \\
\text { Skype, Microsoft } \\
\text { Teams }\end{array}$ \\
\hline $\begin{array}{l}\text { Conferência } \\
\text { multimodal }\end{array}$ & $\begin{array}{l}\text { Tecnologia para interação de grupos em tempo } \\
\text { real, podendo utilizar diversos tipos de mídias, } \\
\text { como áudio e vídeo, texto, lousa digital, entre } \\
\text { outros (SERVIN; DE BRUN, 2005; OROFINO, 2010). }\end{array}$ & $\begin{array}{l}\text { Skype, Hangouts, } \\
\text { Scopia, conferência via } \\
\text { equipamentos de } \\
\text { vídeo conferência, } \\
\text { WhatsApp, } \\
\text { Messenger, Zoom, } \\
\text { Microsoft Teams }\end{array}$ \\
\hline E-mail & $\begin{array}{l}\text { Ferramenta colaborativa onde mensagens são } \\
\text { enviadas através da web e podem ser adicionados } \\
\text { anexos. Tais cópias de documentos e apresentações } \\
\text { podem ser usadas entre indivíduos ou para } \\
\text { transmitir mensagens para um público mais amplo } \\
\text { (SERVIN; DE BRUN, 2005). }\end{array}$ & $\begin{array}{l}\text { Gmail, Hotmail } \\
\text { (Outlook), para e-mail } \\
\text { de pessoa para pessoa } \\
\text { Google Groups, listas } \\
\text { institucionais, para e- } \\
\text { mail list } \\
\text { Mailchimp, } \\
\text { GetResponse - para } \\
\text { envio de e-mail } \\
\text { marketing }\end{array}$ \\
\hline Groupware & $\begin{array}{l}\text { Software projetado especificamente para grupos de } \\
\text { pessoas, não apenas indivíduos, que permite que } \\
\text { grupos de pessoas compartilhem informações e } \\
\text { coordenem suas atividades em uma rede de } \\
\text { computadores. Incluem banco de dados } \\
\text { compartilhado, onde os membros da equipe podem } \\
\text { trabalhar em documentos comuns e realizar } \\
\text { discussões eletrônicas. Alguns incluem calendários } \\
\text { e e-mails (SERVIN; DE BRUN, 2005). }\end{array}$ & $\begin{array}{l}\text { Google Drive, } \\
\text { Microsoft Onedrive, } \\
\text { Google G-Suite }\end{array}$ \\
\hline $\begin{array}{l}\text { Portais do } \\
\text { conhecimento }\end{array}$ & $\begin{array}{l}\text { Ambiente na web que disponibiliza aplicativos da } \\
\text { gestão do conhecimento para o ambiente } \\
\text { organizacional. Acelera o processo de } \\
\text { aprendizagem e facilita a interação entre o } \\
\text { conhecimento tácito e explícito. Contém } \\
\text { informações estruturadas, redes e comunidades de } \\
\text { conhecimento, fóruns de discussão e espaços de } \\
\text { trabalho colaborativos para encorajar, explorar e } \\
\text { transferir mais uma troca espontânea de } \\
\text { conhecimento tácito (YOUNG, 2010; OROFINO, } \\
\text { 2010). }\end{array}$ & $\begin{array}{l}\text { Wordpress, Joomla, } \\
\text { Wix, website sem } \\
\text { construtor }\end{array}$ \\
\hline Redes Sociais & $\begin{array}{l}\text { Sistema web onde um grupo de pessoas } \\
\text { compartilham uma área comum de interesse, } \\
\text { podendo haver interação entre indivíduos ou } \\
\text { grupos (YOUNG, 2010). }\end{array}$ & $\begin{array}{l}\text { Facebook, Instagram, } \\
\text { YouTube, LinkedIn, } \\
\text { Twitter }\end{array}$ \\
\hline Trabalho & Tecnologias que permitem que o conhecimento e a & Google Drive, \\
\hline
\end{tabular}

Perspectivas em Gestão \& Conhecimento, João Pessoa, v. 10, n. 1, p. 131-151, jan./abr. 2020. 


\begin{tabular}{|l|l|l|}
\hline virtual & $\begin{array}{l}\text { experiência de uma pessoa em um local sejam } \\
\text { diretamente aplicados em outro local em tempo } \\
\text { real. Tais tecnologias permitem que o } \\
\text { conhecimento não seja apenas compartilhado, mas } \\
\text { aplicado remotamente (SERVIN; DE BRUN, 2005). }\end{array}$ & $\begin{array}{l}\text { Microsoft Onedrive, } \\
\text { Skype, Hangout }\end{array}$ \\
\hline Vídeo & $\begin{array}{l}\text { Tecnologias para a produção e publicação de vídeos } \\
\text { como meio de captura e compartilhamento de } \\
\text { conhecimento (YOUNG, 2010). }\end{array}$ & $\begin{array}{l}\text { Adobe Premiere, Sony } \\
\text { Vegas, Instagram, } \\
\text { Youtube }\end{array}$ \\
\hline VOIP & $\begin{array}{l}\text { Tecnologias capazes de enviar sinais de áudio e } \\
\text { vídeo entre computadores, usando nada além de } \\
\text { uma conexão de banda larga e alguns } \\
\text { equipamentos de baixo custo, como webcam e fone } \\
\text { de ouvido (YOUNG, 2010). }\end{array}$ & $\begin{array}{l}\text { Skype, Hangouts, } \\
\text { Scopia, WhatsApp, } \\
\text { Messenger, Zoom, } \\
\text { Microsoft Teams }\end{array}$ \\
\hline Wiki & $\begin{array}{l}\text { Espaço virtual para a construção do conhecimento } \\
\text { coletivo de forma colaborativa (YOUNG, 2010). }\end{array}$ & $\begin{array}{l}\text { MediaWiki, TikiWiki, } \\
\text { ProProfs Wiki } \\
\text { Software }\end{array}$ \\
\hline
\end{tabular}

Fonte: Elaborado pelos autores

O Quadro 2 expõe uma apresentação de cada uma das ferramentas citadas no Quadro 1. As informações foram retiradas dos sites institucionais de cada ferramenta, onde buscou-se ferramentas que possuíssem funcionalidades para se adequar aos métodos propostos.

Quadro 2 - Descrição das ferramentas

\begin{tabular}{|c|c|}
\hline Google Drive & $\begin{array}{l}\text { Sistema de armazenamento de arquivos em nuvem, com 15GB de } \\
\text { armazenamento gratuito. Possibilita a criação online de arquivos de texto, } \\
\text { planilha, apresentação, formulário e outros, que podem ser editados de maneira } \\
\text { colaborativa em tempo real, com opção de conversa entre os colaboradores } \\
\text { (GOOGLE, 2020a). }\end{array}$ \\
\hline $\begin{array}{l}\text { Microsoft } \\
\text { OneDrive }\end{array}$ & $\begin{array}{l}\text { Sistema de armazenamento de arquivos em nuvem, com 5GB de armazenamento } \\
\text { gratuito. Possibilita a criação online de arquivos de texto, planilhas e } \\
\text { apresentações. Possui sistema de compartilhamento e colaboração em tempo } \\
\text { real (MICROSOFT, 2020a). }\end{array}$ \\
\hline Moodle & $\begin{array}{l}\text { Plataforma de aprendizado projetada para fornecer à educadores, } \\
\text { administradores e alunos um único sistema integrado para criar ambientes de } \\
\text { aprendizado personalizados. Sistema de código aberto sob licença GNU (General } \\
\text { Public License), onde é possível realizar a instalação em servidor próprio } \\
\text { (MOODLE, 2020). }\end{array}$ \\
\hline $\begin{array}{l}\text { Google Sala de } \\
\text { Aula }\end{array}$ & $\begin{array}{l}\text { Ferramenta que possibilita professores a gerenciar atividades de ensino. } \\
\text { Possibilita a criação de turmas, distribuição de tarefas, notas e enviar feedbacks } \\
\text { (GOOGLE, 2020b). }\end{array}$ \\
\hline Blackboard & $\begin{array}{l}\text { Plataforma de gestão de aprendizado que permite a criação de cursos online, } \\
\text { atribuição de papeis para gestores, criação e monitoramento de atividades } \\
\text { (BLACKBOARD, 2020). }\end{array}$ \\
\hline Google Groups & $\begin{array}{l}\text { Plataforma que permite a criação de grupos online que permite o envio coletivo } \\
\text { de e-mails e criar e participar de discussões online (GOOGLE, 2020c). }\end{array}$ \\
\hline $\begin{array}{l}\text { Fórum de } \\
\text { ambiente virtual } \\
\text { de } \\
\text { aprendizagem }\end{array}$ & $\begin{array}{l}\text { Ferramentas de e-learning, como Moodle, Google Sala de Aula e Blackboard, } \\
\text { possibilitam a criação de fóruns de discussão dentro de seus ambientes, sendo } \\
\text { uma ferramenta integrada ao método de e-learning. As ferramentas possibilitam } \\
\text { a criação de um tópico por participantes onde outros podem responder e iniciar } \\
\text { uma discussão sobre o tema (BLACKBOARD, 2020; GOOGLE, 2020b; MOODLE, } \\
\text { 2020). }\end{array}$ \\
\hline
\end{tabular}

Perspectivas em Gestão \& Conhecimento, João Pessoa, v. 10, n. 1, p. 131-151, jan./abr. 2020. 


\begin{tabular}{|c|c|}
\hline $\begin{array}{l}\text { Grupos de } \\
\text { Facebook }\end{array}$ & $\begin{array}{l}\text { Comunidades criadas dentro da rede social Facebook para o compartilhamento } \\
\text { de interesses em comum entro um público. Dentro do grupo é possível fazer } \\
\text { publicações com diferentes mídias, texto, imagem, vídeo ou arquivo, onde } \\
\text { usuários podem responder e interagir (FACEBOOK, 2020a). }\end{array}$ \\
\hline Reddit & $\begin{array}{l}\text { Espaço virtual para a criação de comunidades para a troca de informações e } \\
\text { conhecimentos. Nela é possível criar postagens, criar votações e comentar em } \\
\text { postagens organizadas por tópicos (REDDIT, 2020). }\end{array}$ \\
\hline Lattes & $\begin{array}{l}\text { Plataforma de integração de bases de dados de currículos, de grupos de pesquisa } \\
\text { e de instituições em um único sistema de informações. É a plataforma padrão } \\
\text { nacional no registro da vida pregressa e atual dos estudantes e pesquisadores do } \\
\text { Brasil, e é hoje adotado pela maioria das instituições de fomento, universidades e } \\
\text { institutos de pesquisa do país (CNPQ, 2020). }\end{array}$ \\
\hline Linkedin & $\begin{array}{l}\text { Linkedin é uma rede social de profissional. Na rede é possível criar perfil pessoal } \\
\text { profissional, com formação, habilidades e experiências prévias, e conectar ou } \\
\text { outros profissionais e páginas de empresas. O Linkedin possibilita a oferta e } \\
\text { procura de vagas assim como o compartilhamento de conhecimento (LINKEDIN, } \\
\text { 2020). }\end{array}$ \\
\hline ResearchGate & $\begin{array}{l}\text { Rede profissional para cientistas e pesquisadores. Na rede é possível } \\
\text { compartilhar, descobrir e discutir pesquisas, além da possibilidade de criar perfis } \\
\text { e conexão com outros pesquisadores (RESEARCHGATE, 2020). }\end{array}$ \\
\hline Wordpress & $\begin{array}{l}\text { Wordpress é um CMS (Content Management System, sistema de gerenciamento } \\
\text { de conteúdo em português) que possibilita criar, editar, gerenciar e publicar } \\
\text { conteúdo sem a necessidade de interação com códigos fontes de páginas, ou o } \\
\text { conhecimento sobre linguagens como HTML e CSS. Com Wordpress é possível } \\
\text { criar desde blogs e sites simples até portais de diferentes páginas e } \\
\text { funcionalidades (WORDPRESS, 2020). }\end{array}$ \\
\hline Wix & $\begin{array}{l}\text { Wix é uma plataforma online para a criação de blogs e sites. Permite a criação de } \\
\text { blogs, com criação e edição de posts, gerenciamento de comentários e } \\
\text { compartilhamento nas redes sociais (WIX, 2020). }\end{array}$ \\
\hline Joomla & $\begin{array}{l}\text { Joomla é um CMS gratuito e de código aberto para a publicação de conteúdo na } \\
\text { web. Permite a criação de sites de diferentes portes, e uma completa biblioteca } \\
\text { de modelos de blogs disponíveis (JOOMLA, 2020). }\end{array}$ \\
\hline Blogger & $\begin{array}{l}\text { Ferramenta gratuita online para a criação de blogs a partir de modelos acessíveis } \\
\text { e flexíveis disponibilizados. Permite a criação de postagem, gestão de conteúdo } \\
\text { como textos, imagens e vídeos e o gerenciamento de comentário nas páginas } \\
\text { (GOOGLE, 2020d). }\end{array}$ \\
\hline $\begin{array}{l}\text { Blog e site sem } \\
\text { CMS }\end{array}$ & $\begin{array}{l}\text { Blog e site construídos com linguagens de programação como PHP, JavaScript, } \\
\text { HTML, CSS, e outras, sem um sistema de auxílio para a gestão do conteúdo, } \\
\text { necessitando ser construído e mantido por pessoa capacitada. }\end{array}$ \\
\hline WhatsApp & $\begin{array}{l}\text { Aplicativo de envio de mensagens instantâneas de texto, voz e mídias, disponível } \\
\text { para Android e iOS, também com acesso via navegador web. Permite o envio de } \\
\text { mensagem um para um, ou um para muito por meio da criação de grupos. Pelo } \\
\text { aplicativo também é possível realizar chamadas de voz e vídeo. (WHATSAPP, } \\
\text { 2020). }\end{array}$ \\
\hline Messenger & $\begin{array}{l}\text { Aplicativo de troca de mensagens de texto e mídias, documentos, áudios, } \\
\text { imagens e vídeos. Disponível para Android, iOS e navegador web. Permite o envio } \\
\text { de mensagens um para um ou um para muito com a criação de grupos. Possibilita } \\
\text { a realização de chamadas de voz e vídeo (MESSENGER, 2020). }\end{array}$ \\
\hline Hangouts & $\begin{array}{l}\text { Hangouts possui duas funcionalidades integradas uma única ferramenta, } \\
\text { Hangouts Chat, para troca de mensagens simultâneas e Hangouts Meet para } \\
\text { vídeo conferências. O Chat permite que equipes colaborarem de modo fácil e } \\
\text { eficiente usando mensagens diretas e conversas em grupo (GOOGLE, 2020e). O } \\
\text { Meet permite a criação de salas para vídeo chamadas, onde também é possível a } \\
\text { troca de mensagens de texto (GOOGLE, 2020f). }\end{array}$ \\
\hline
\end{tabular}

Perspectivas em Gestão \& Conhecimento, João Pessoa, v. 10, n. 1, p. 131-151, jan./abr. 2020. 


\begin{tabular}{|c|c|}
\hline Telegram & $\begin{array}{l}\text { Aplicativo de troca de mensagens que possibilita a troca de mensagens, fotos, } \\
\text { vídeos e arquivos. Permite a criação de grupos para troca de mensagens um para } \\
\text { muitos, e suporte chamadas de voz (TELEGRAM, 2020). }\end{array}$ \\
\hline Slack & $\begin{array}{l}\text { Ferramenta de troca de mensagens disponível em aplicativo Android e iOS, e em } \\
\text { navegador web. Estruturado em formato de canais que podem ser criados entre } \\
\text { indivíduos ou equipes inteiras. Também possibilita chamadas de voz e vídeo } \\
\text { (SLACK, 2020). }\end{array}$ \\
\hline Skype & $\begin{array}{l}\text { Ferramenta que permite a troca de mensagens um para um ou um para muitos, } \\
\text { chamadas de voz e vídeo e chamadas telefônicas (SKYPE, 2020). }\end{array}$ \\
\hline Microsoft Teams & $\begin{array}{l}\text { Ferramenta de troca de mensagens, um para um ou um para muitos. Possibilita } \\
\text { também chamadas de voz e vídeo (MICROSOFT, 2020b). }\end{array}$ \\
\hline Scopia & $\begin{array}{l}\text { Software de vídeo chamada que permite a comunicação de computadores com } \\
\text { aparelhos de videoconferência (AVAYA, 2020). }\end{array}$ \\
\hline $\begin{array}{l}\text { Conferência via } \\
\text { equipamentos } \\
\text { de } \\
\text { videoconferência }\end{array}$ & $\begin{array}{l}\text { Hardwares específicos para comunicação de voz e vídeo conectando dois pontos, } \\
\text { ou utilizando software para controle de múltiplos pontos. }\end{array}$ \\
\hline Zoom & $\begin{array}{l}\text { Software de comunicação em nuvem para videoconferência, áudio e chat (ZOOM, } \\
\text { 2020). }\end{array}$ \\
\hline Gmail & $\begin{array}{l}\text { Serviço de troca de e-mails da empresa Google. Em sua versão gratuita } \\
\text { disponibiliza 15GB de armazenamento (GOOGLE, 2020g). }\end{array}$ \\
\hline Outlook & $\begin{array}{l}\text { Serviço de e-mail da empresa Microsoft, que disponibiliza 15BG de } \\
\text { armazenamento em sua versão gratuita (MICROSOFT, 2020c). }\end{array}$ \\
\hline $\begin{array}{l}\text { Listas } \\
\text { Institucionais }\end{array}$ & $\begin{array}{l}\text { Softwares para gerenciamento de listas de discussão por e-mail e boletins } \\
\text { eletrônicos. Muitas vezes integrados aos provedores de e-mail institucionais. }\end{array}$ \\
\hline Mailchimp & $\begin{array}{l}\text { Ferramenta para a criação e envio de e-mail para grupos de contatos, } \\
\text { possibilitando a automação e visualização de resultados (MAILCHIMP, 2020). }\end{array}$ \\
\hline GetResponse & $\begin{array}{l}\text { Ferramenta para criação, envio e automação de envio de e-mail para grupos } \\
\text { (GETRESPONSE, 2020). }\end{array}$ \\
\hline Google G-Suite & $\begin{array}{l}\text { Solução com integração de diferentes ferramentas, como agenda, edição } \\
\text { compartilhada de documentos de texto, planilhas e apresentações, chat, } \\
\text { chamadas de áudio e vídeo (GOOGLE, 2020h). }\end{array}$ \\
\hline Facebook & $\begin{array}{l}\text { Rede social que permite a conexão de pessoas, empresas e grupos com interesses } \\
\text { em comum (FACEBOOK, 2020b). }\end{array}$ \\
\hline Instagram & $\begin{array}{l}\text { Rede social baseada no compartilhamento de fotos e vídeos. Permite a conexão } \\
\text { entre perfil pessoais e também comerciais (INSTAGRAM, 2020). }\end{array}$ \\
\hline YouTube & $\begin{array}{l}\text { Plataforma para o compartilhamento de vídeos. Permite a conexão entre usuários } \\
\text { e canais de vídeos e interação entre usuários por meio de comentários e tópicos } \\
\text { de discussão (GOOGLE, 2020i). }\end{array}$ \\
\hline Twitter & $\begin{array}{l}\text { Rede social baseada no compartilhamento de mensagens curtas, e também de } \\
\text { fotos e vídeos. Possibilita a interação entre mensagem e a conexão entre usuários } \\
\text { (TWITTER, 2020). }\end{array}$ \\
\hline Adobe Premiere & Ferramenta de produção e edição de vídeos (ADOBE, 2020). \\
\hline Vegas Pro & Ferramenta de produção e edição de vídeos (MAGIX, 2020). \\
\hline MediaWiki & $\begin{array}{l}\text { Software para a criação de wikis. Permite coletar e organizar o conhecimento e } \\
\text { torná-lo disponível, sendo gratuito e aberto (MEDIAWIKI, 2020). }\end{array}$ \\
\hline TikiWiki & Software CMS focado na criação de wikis (TIKI, 2020). \\
\hline $\begin{array}{l}\text { ProProfs Wiki } \\
\text { Software }\end{array}$ & Software para a criação de wikis corporativas (PROPROFS, 2020). \\
\hline
\end{tabular}

Fonte: elabora pelos autores

Servin e De Brun, (2005) e Young (2010) mencionam o método chamado de centro de conhecimento como um meio de compartilhamento de conhecimento, não foi encontrado na

Perspectivas em Gestão \& Conhecimento, João Pessoa, v. 10, n. 1, p. 131-151, jan./abr. 2020. 
literatura, e em outros documentos, exemplo de uma única ferramenta que se adeque a este método. Este é um exemplo de método que uma única ferramenta não é capaz de alcançar os objetivos propostos, sendo necessária a utilização de um conjunto de TIC ou a modelagem e construção de uma ferramenta específica. A seção seguinte discute e analisa os resultados alcançados.

\section{ANÁLISE E DISCUSSÃO DOS RESULTADOS}

Os autores no quadro 1 (SERVIN; DE BRUN, 2005; YOUNG, 2010) discorrem sobre como incluir estes métodos e técnicas nas rotinas de trabalho das organizações, da cultura envolvida para suas aplicações. Porém, pouco é discutido a respeito de ferramentas que podem cumprir este papel, e principalmente como podem ser implantadas e utilizadas a fim de otimizar os objetivos da organização.

Para Servin e De Brun (2005), os três componentes, processos, pessoas e tecnologia, são partes interdependentes e imprescindíveis para o sucesso da gestão do conhecimento em qualquer organização, sendo a tecnologia um meio viabilizar e apoios os processos apropriados para a GC. A gestão de TIC faz parte dos aspectos de gestão da organização. A fraca gestão das TIC contribui para a dificuldade de alcançar os objetivos e o baixo desempenho da organização. Um dos principais bens utilizados pelas TIC é o conhecimento, que precisa ser gerenciado para manter a memória da organização (MUDA; YUSOF, 2015). Para Dagli, Silman e Birol (2009), dentro das universidades o gerenciamento de conhecimento, deve ser realizado com ferramentas que motivem o processo de aprendizagem. Muda e Yusof (2015) afirmam que a escolha e utilização correta das TIC no processo de compartilhamento de conhecimento o torna mais efetivo e menos custosos, para organização e os indivíduos envolvidos. Assim, o gerenciamento do conhecimento bem-sucedido depende de como as ferramentas e recursos informacionais são efetivamente aplicadas (DAGLI; SILMAN; BIROL, 2009).

Desta forma, nas universidades e grupos de pesquisa, a utilização correta de TIC se mostra imprescindível para tornar efetivos os processos do conhecimento e fortalecer o aprendizado dos participantes. Grande parte das ferramentas apresentadas na seção anterior são gratuitas, ou possuem versões gratuitas, fator importante para instituições de ensino e grupos de pesquisa que trabalham, normalmente, com restrições financeiras (LICHTNOW, 2001).

Dentro dos métodos baseados em TIC abordados na pesquisa há os mais propícios para o compartilhamento de conhecimento interno à instituição (entre os membros da universidade ou grupo de pesquisa), e aqueles que possuem um maior potencial para o compartilhamento externo (da instituição ou grupo para a sociedade). Como métodos mais propícios para o compartilhamento interno é possível destacar: comunidades virtuais de execução de projetos, gerenciamento de conteúdo, chat, VOIP, groupware e trabalho virtual. A ferramentas para este método possuem as características necessárias para auxiliar nos processos de compartilhamento interno, como preservação (GOERGEN, 1998), gerenciamento (FREITAS JUNIOR, 2017) e criação (GOERGEN, 1998) de conhecimento, trabalho colaborativo (OLIVEIRA, 2006; AGUIR; FILHO; NASSIF, 2016), interação (VANZ; STUMPF, 2010; FILHO; NASSIF, 2016) e comunicação (LIN, 2007) entre os indivíduos. O compartilhamento de conhecimento interno melhora o desempenho individual e a eficácia da equipe (LIU; KELLER; $\mathrm{SHIH}, 2011)$. Equipes que trabalham com pesquisa possuem indivíduos com conhecimentos diferentes, quando a complementaridade do conhecimento dos membros da equipe é compartilhada e transferida para a equipe como um todo, o conhecimento coletivo é desenvolvido (ZÁRRAGA; BONACHE, 2003; LIU; KELLER; SHIH, 2011).

Perspectivas em Gestão \& Conhecimento, João Pessoa, v. 10, n. 1, p. 131-151, jan./abr. 2020. 
Entre métodos de GC para o compartilhamento externo, destaca-se: fórum, redes sociais, vídeos, e-learning, páginas brancas ou amarelas, blog, portais do conhecimento e wiki. Estas ferramentas possuem as características que auxiliam os processos necessários para a efetividade do compartilhamento com externo, como possibilidade de interatividade (SANTOS; ALMEIDA FILHO, 2008; VANZ; STUMPF, 2010) e integração de diferentes públicos (VON ZUBEN, 1995), recuperação de conhecimento (LIN, 2007), e proporcionar visibilidade as instituições (LEITE et al., 2009). As universidades e os seus pesquisadores não são somente criadores de conhecimento, são também os responsáveis pela maneira que esse conhecimento chega e é utilizado pela sociedade (MEIS; LETA, 1996). Desta forma a tecnologia é um elemento essencial na realização de pesquisas para se alcançar esses objetivos (ASSEGAFF, 2017). A web 2.0 permitiu uma maior participação dos leitores e públicos em geral que utilizam estas ferramentas, sendo o seu pilar fundamental a interação (CORREA, 2012).

As ferramentas apresentadas nesta pesquisa integram a web 2.0 e possibilitam uma comunicação de maneira interativa das instituições de pesquisa com a sociedade (CORREA, 2012). Em grande parte, pelo fato de não serem ferramentas exclusivas, ou utilizadas somente na área acadêmica. São ferramentas populares, e até de uso cotidiano de grande parte da sociedade. O papel social da universidade e do cientista proposto por Meis e Leta (1996) como decodificadores do saber precede a web 2.0. Estas tecnologias criadas e popularizadas nas duas últimas décadas facilitam e reforçam a necessidade dos pesquisadores alcançarem a sociedade com o que é produzido na academia.

Para isto, é necessário o engajamento dos indivíduos gestores, principalmente dos grupos de pesquisa, os professores líderes. A mudança de atitude dos professores é fundamental para a mudança de atitude frente a utilização das tecnologias no contexto educacional (COSTA; VISEU, 2008), sendo o estímulo docente um fator de influência para a criação do hábito de utilização neste contexto (YAMANAKA; CAPPELLOZZA, 2018). Somente com a mudança de postura dos integrantes das instituições e um processo de aprendizado será possível criar hábito de utilização em diferentes níveis, de forma a inclui-las no comportamento dos grupos (VENKATESH; THONG; XU, 2012). Quando o hábito de utilização destas tecnologias estiver fixado no grupo, com integrantes envolvidos em compartilhar conhecimento, a cultura da gestão e compartilhamento do conhecimento será evidenciada (SERVIN; DE BRUN, 2005; RABABAH et al., 2013), assim favorecendo a decodificação do conhecimento e a sua utilização pela sociedade (GOERGEN, 1998; OLIVEIRA et al., 2006).

\section{CONSIDERAÇÕES FINAIS}

Este trabalho buscou explorar o papel das instituições de pesquisa no compartilhamento de conhecimento científico. Para isto também apresenta um conjunto de ferramentas aliadas aos métodos e técnicas de gestão do conhecimento (GC) para auxiliar o processo de compartilhamento de conhecimento de instituições de pesquisa para a sociedade, como uma forma de decodificação do conhecimento científico. Foram identificados 16 métodos e técnicas de GC baseados em TIC na literatura, e mais de 40 ferramentas únicas que podem auxiliar na sua execução. As ferramentas identificadas são populares e de uso comum, ao contrário das utilizadas no meio acadêmico, que ficam restritas a este meio. Isto propicia uma maior facilidade de utilização e aceitação pelos dois públicos distintos, as instituições de pesquisa e a sociedade em geral. Isto se deve pelas características de compartilhamento de conhecimento que possuem, entre elas a capacidade de interatividade e integração de diferentes públicos, recuperação de conhecimento e capacidade de dar visibilidade a estas instituições.

O papel das instituições de pesquisa, como as universidades, sofreu inúmeras mudanças com o passar dos séculos. E desde o fim do século XX e com a popularização das TIC

Perspectivas em Gestão \& Conhecimento, João Pessoa, v. 10, n. 1, p. 131-151, jan./abr. 2020. 
a universidade necessita construir o conhecimento de maneira interativa com a sociedade. A utilização das ferramentas apresentadas auxilia no processo de decodificação e democratização do conhecimento gerado nas instituições, aproximando os diferentes atores da sociedade, para construir um conhecimento mais utilitário.

Foi possível notar na literatura que os conceitos de métodos e técnicas de GC baseados em TIC são os mesmos utilizados a mais de uma década. Com o rápido avanço tecnológico, e principalmente das redes sociais, a utilização das tecnologias para estes propósitos veem sofrendo alterações, porém os conceitos e recomendações de ferramentas são os mesmos a mais de dez anos. Este trabalho contribui demonstrando a importância dos grupos de pesquisa e das universidades como disseminadores do conhecimento, ressaltando os seus papeis de desenvolvedores e decodificadores do saber. E para isto foi constatado que existem ferramentas que se adequam as peculiaridades organizacionais destas instituições e possuem as características necessárias para compartilhar conhecimento com a sociedade.

\section{AGRADECIMENTOS}

O presente trabalho foi realizado com apoio da Coordenação de Aperfeiçoamento de Pessoal de Nível Superior - Brasil (CAPES).

\section{REFERÊNCIAS}

ADOBE. Premiere. Disponível em: https://www.adobe.com/br/products/premiere.html. Acesso em: 09 abr. 2020.

AGUIAR FILHO, A. S.; NASSIF, M. E. O papel dos grupos de apoio e o compartilhamento da informação e do conhecimento nas avaliações das instituições de ensino superior privadas. Perspectivas em Ciência da Informação, Belo Horizonte, v. 21, n. 3, p. 182-203, set. 2016.

ASSEGAFF, S. Social Media Success for Academic Knowledge Sharing in Indonesia (Conceptual Model Development). In: IOP Conference Series: Materials Science and Engineering. IOP Publishing, 2017.

BJÖRK, B. A model of scientific communication of a global distributed information system. 2007.

BLACKBOARD. Feature Guide. Disponível em: https://help.blackboard.com/ptbr/Blackboard Instructor/Feature Guide. Acesso em: 09 abr. 2020.

CHAUÍ, M. A universidade pública sob nova perspectiva. Revista Brasileira de Educação, v. 24, p. 5-15, 2003.

CNPQ. Sobre a Plataforma Lattes. Disponível em: http://memoria.cnpq.br/web/portallattes/sobre-a-plataforma;jsessionid=7534E4D443044B99B7357EF41273A076. Acesso em: 09 abr. 2020.

CORREA, E. C. D. Os artigos científicos em tempos de Web 2.0: uma reflexão teórica. Revista ACB, v. 17, n. 1, p. 42-58, 2012.

Perspectivas em Gestão \& Conhecimento, João Pessoa, v. 10, n. 1, p. 131-151, jan./abr. 2020. 
COSTA, F. A.; VISEU, S. Formação-Acção-Reflexão: Um modelo de preparação de professores para a integração curricular das TIC. As TIC na Educação em Portugal. Concepções e práticas, p. $238-258,2008$.

DAGLI, G.; SILMAN, F.; BIROL, C. A Qualitative Research Regarding the University Administrators' Capacity to Use of Management Information Tools. Procedia Social and Behavioral Sciences, v. 1, p. 2480-2490, 2009.

DALKIR, K. Knowledge management in theory and practice. Routledge, 2013.

DAVENPORT, T.; PRUSAK, L. Working knowledge: How organizations manage what they know. Harvard Business Press, 1998.

DI CHIARA, I.; ALCARÁ, A.; TOMAÉL, M. Tipos de compartilhamento de informação e do conhecimento no ambiente de P\&D. Informação \& Sociedade, v. 20, n. 2, 2010.

EID, M.; NUHU, N. A. Impact of learning culture and information technology use on knowledge sharing of Saudi students. Knowledge Management Research \& Practice, v. 9, n. 1, p. 48-57, 2011.

FACEBOOK. Facebook App. Disponível em: https://about.fb.com/technologies/facebook-app/.. Acesso em: 09 abr. 2020b.

FACEBOOK. Sobre Grupos. Disponível em: https://www.facebook.com/help/1629740080681586/?helpref=hc fnav. Acesso em: 09 abr. 2020a.

FREITAS JÚNIOR, O. et al. Uma Arquitetura para Sistemas de Gestão do Conhecimento Orientada a Grupos De Pesquisa e Desenvolvimento. Perspectivas em Gestão \& Conhecimento, v. 7, n. 1, p. 126-144, 2017.

FULLWOOD, R.; ROWLEY, J.; DELBRIDGE, R. Knowledge sharing amongst academics in UK universities. Journal of Knowledge Management, v. 17, n. 1, p. 123-136, 2013.

GETRESPONSE. Marketing por e-mail. Disponível em: https://br.getresponse.com/emailmarketing/nossos-recursos/marketing-por-e-mail. Acesso em: 09 abr. 2020.

GIL, A. C. Métodos e técnicas de pesquisa social. 6. ed. Editora Atlas SA, 2008.

GOERGEN, P. Ciência, sociedade e universidade. Educação e sociedade, v. 19, n. 63, p. 53-79, 1998.

GOOGLE. About Gmail. Disponível em: https://www.google.com/intl/pt-BR/gmail/about/. Acesso em: 09 abr. 2020g.

GOOGLE. Ajuda do Grupos do Google. Disponível em: https://support.google.com/groups/answer/2464926?hl=pt. Acesso em: 09 abr. 2020c.

GOOGLE. Central de Ajuda Blogger. Disponível em: https://support.google.com/blogger/?p=help home\&hl=pt\&authuser=0\#topic=3339243.

Acesso em: 09 abr. 2020d.

Perspectivas em Gestão \& Conhecimento, João Pessoa, v. 10, n. 1, p. 131-151, jan./abr. 2020. 
GOOGLE. Central de Ajuda Youtube. Disponível em: https://support.google.com/youtube/\#topic=9257498. Acesso em: 09 abr. 2020i.

GOOGLE. Gerencie o ensino e a aprendizagem com o Sala de Aula. Disponível em: https://edu.google.com/intl/pt-BR/products/classroom/?modal active=none. Acesso em: 09 abr. 2020b.

GOOGLE. Google Drive. Disponível em: https://www.google.com/intl/pt-PT ALL/drive/usingdrive/. Acesso em: 09 abr. 2020a.

GOOGLE. G-Suite Features. Disponível em: https://gsuite.google.com.br/intl/pt-BR/features/. Acesso em: 09 abr. 2020h.

GOOGLE. Hangouts Chat. Disponível em: https://gsuite.google.com/intl/pt-BR/products/chat/. Acesso em: 09 abr. 2020e.

GOOGLE. Meet. Disponível em: https://gsuite.google.com.br/intl/pt-BR/products/meet/. Acesso em: 09 abr. $2020 f$.

INSTAGRAM. Features. Disponível em: https://about.instagram.com/features. Acesso em: 09 abr. 2020.

JONSSON, A. A transnational perspective on knowledge sharing: lessons learned from IKEA's entry into Russia, China and Japan. The international review of retail, Distribution and Consumer Research, v. 18, n. 1, p. 17-44, 2008.

JOOMLA. About Joomla. Disponível em: https://www.joomla.org/about-joomla.html. Acesso em: 09 abr. 2020.

LEITE, F. C. L. et al. Como gerenciar e ampliar a visibilidade da informação científica brasileira: repositórios institucionais de acesso aberto. Fernando César Lima Leite. - Brasília: Ibict, 2009.

LEITE, F.; COSTA, S. S. Gestão do conhecimento científico: proposta de um modelo conceitual com base em processos de comunicação científica. Ciência da Informação, v. 36, n. 1, 2007.

LICHTNOW, D. Desenvolvimento e implementação de um protótipo de ferramenta para gestão do conhecimento em grupos de pesquisa. 2001. 164 f. Dissertação (Mestrado em Computação) - Universidade Federal de Santa Catarina, Florianópolis, 2001.

LIN, H. Knowledge sharing and firm innovation capability: an empirical study. International Journal of manpower, v. 28, n. 3/4, p. 315-332, 2007.

LINKEDIN. What is LinkedIn and How Can I Use It? Disponível em: https://www.linkedin.com/help/linkedin/answer/111663/what-is-linkedin-and-how-can-i-useit-?lang=em. Acesso em: 09 abr. 2020.

LIU, Y.; KELLER, R. T.; SHIH, H. The impact of team-member exchange, differentiation, team commitment, and knowledge sharing on R\&D project team performance. R\&D Management, v. 41, n. 3, p. 274-287, 2011.

Perspectivas em Gestão \& Conhecimento, João Pessoa, v. 10, n. 1, p. 131-151, jan./abr. 2020. 
LOGREIRA, H.; MUSA, R.; ZAPATA, J. Relation Analysis of Knowledge Management, Research, and Innovation in University Research Groups. Journal of Technology Management \& Innovation, v. 11, n. 4, p. 5-11, 2016.

MACHADO, N. J. A Universidade e a organização do conhecimento: a rede, o tácito, a dádiva. Estudos avançados, v. 15, n. 42, p. 333-352, 2001.

MAGIX. Vegas Pro. Disponível em: https://www.vegascreativesoftware.com/br/vegas-pro/. Acesso em: 09 abr. 2020.

MAILCHIMP. Features. Disponível em: https://mailchimp.com/features/email/. Acesso em: 09 abr. 2020.

MARCONI, M. A.; LAKATOS, E. M. Fundamentos de metodologia científica. 5. ed. São Paulo: Atlas, 2003.

MEDIAWIKI. MediaWiki. Disponível em: https://www.mediawiki.org/wiki/MediaWiki. Acesso em: 09 abr. 2020

MEIS, L.; LETA, J. O perfil da ciência brasileira. Rio de Janeiro, Ed. UFRJ, 1996.

MESSENGER. Features. Disponível em: https://www.messenger.com/features. Acesso em: 09 abr. 2020.

MICROSOFT. Microsoft One Drive Planos. Disponível em: https://products.office.com/ptbr/onedrive/compare-onedrive-plans?activetab=tab:primaryr1. Acesso em: 09 abr. 2020a.

MICROSOFT. Microsoft Teams recursos. Disponível em: https://products.office.com/pt$\mathrm{br} /$ microsoft-teams/get-started-working-remotely. Acesso em: 09 abr. $2020 \mathrm{~b}$.

MICROSOFT. Outlook help \& learning. Disponível em: https://support.office.com/enus/outlook. Acesso em: 09 abr. 2020c.

MOODLE. About Moodle. Disponível em: https://docs.moodle.org/38/en/About Moodle. Acesso em: 09 abr. 2020.

MUDA, M.; YUSOF, Z. Information and Communication Technology (ICT) in Knowledge Sharing Practices: Needs for the Establishment of Repository. Mediterranean Journal of Social Science, v. 6, n. 5, p. 69, 2015.

OLIVEIRA, J. et al. GCC: A knowledge management environment for research centers and universities. In: Asia-Pacific Web Conference. Springer, Berlin, Heidelberg, 2006. p. 652-667.

OROFINO, M. Técnicas de criação do conhecimento no desenvolvimento de modelos de negócio. 2011. 223 f. Dissertação (Mestrado Engenharia e Gestão do Conhecimento) Universidade Federal de Santa Catarina, Florianópolis, 2011.

PAULIN, D.; SUNESON, K. Knowledge transfer, knowledge sharing and knowledge barriersthree blurry terms in KM. The Electronic Journal of Knowledge Management, v. 10, n. 1, p. 8191, 2012.

Perspectivas em Gestão \& Conhecimento, João Pessoa, v. 10, n. 1, p. 131-151, jan./abr. 2020. 
PROPROFS. Wiki Software. Disponível em: https://www.proprofs.com/knowledgebase/wikisoftware/. Acesso em: 09 abr. 2020.

RABABAH, O. et al. Utilizing Knowledge Management in Education: The Case of" The University of Jordan". International Journal of Emerging Technologies in Learning, v. 8, n. 1, 2013.

RAYMOND, C. et al. Integrating local and scientific knowledge for environmental management. Journal of Environmental Management, v. 91, n. 8, p. 1766-1777, 2010.

REDDIT. Reddit about. Disponível em: https://www.redditinc.com/. Acesso em: 09 abr. 2020.

RESEARCHGATE. About. Disponível em: https://www.researchgate.net/about. Acesso em: 09 abr. 2020.

RIVERA, G.; RIVERA, I. Design, measurement and analysis of a Knowledge Management model in the context of a Mexican University. Innovar, v. 26, n. 59, p. 21-34, 2016.

SANTOS, B. S.; ALMEIDA FILHO, N. de. A universidade no século XXI: para uma universidade nova. 2008.

SCOPIA. Scopia. Disponível em: https://support.avaya.com/products/P1421/scopiadesktop/8.2.1. Acesso em: 09 abr. 2020.

SCOPUS. Scopus Content at-a-glance. Disponível em: < https://www.elsevier.com/solutions/scopus/how-scopus-works/content. Acesso em: 01 de maio de 2019.

SERVIN, G.; DE BRUN, C. ABC of knowledge management. NHS National Library for Health: Specialist Library, 2005.

SKYPE. Features. Disponível em: https://www.skype.com/pt-br/features/. Acesso em: 09 abr. 2020.

SLACK. Features. Disponível em: https://slack.com/intl/pt-br/features. Acesso em: 09 abr. 2020.

TAKEUCHI, H.; NONAKA, I. Gestão do conhecimento. Bookman Editora, 2008.

TAN, C.; NOOR, S. Knowledge management enablers, knowledge sharing and research collaboration: a study of knowledge management at research universities in Malaysia. Asian Journal of Technology Innovation, v. 21, n. 2, p. 251-276, 2013.

TELEGRAM. Telegram FAQ. Disponível em: https://telegram.org/faq\#q-what-is-telegram-whatdo-i-do-here. Acesso em: 09 abr. 2020.

TIKI. Tiki Features. Disponível em: https://tiki.org/Features. Acesso em: 09 abr. 2020.

TWITTER. Como usar. Disponível em: https://help.twitter.com/pt/using-twitter. Acesso em: 09 abr. 2020.

Perspectivas em Gestão \& Conhecimento, João Pessoa, v. 10, n. 1, p. 131-151, jan./abr. 2020. 
VAN DEN HOOFF, B.; HUYSMAN, M. Managing knowledge sharing: Emergent and engineering approaches. Information \& management, v. 46, n. 1, p. 1-8, 2009.

VANZ, S. A. S.; STUMPF, I. R. C. Colaboração científica: revisão teórico-conceitual. Perspectivas em Ciência da Informação, Belo Horizonte, v. 15, n. 2, p. 42-55, 2010.

VENKATESH, V.; THONG, J. Y.L.; XU, X. Consumer acceptance and use of information technology: extending the unified theory of acceptance and use of technology. MIS quarterly, p. 157-178, 2012.

VON ZUBEN, N. A relevância da iniciação à pesquisa científica na universidade. Proposições, v. 6, n. 2, p. 5-18, 1995.

WANDERLEY, L. E. W. O que é universidade. 1. ed. Taubaté: Brasiliense, 2017.

WEB OF SCIENCE. About. Disponível em: https://clarivate.com/products/web-of-science/. Acesso em: 01 de maio de 2019.

WHATSAPP. Features. Disponível em: https://www.whatsapp.com/features/. Acesso em: 09 abr. 2020.

WIX. Recursos Wix. Disponível em: https://pt.wix.com/features/main. Acesso em: 09 abr. 2020.

WORDPRESS. Recursos. Disponível em: https://br.wordpress.org/about/features/. Acesso em: 09 abr. 2020.

YAMANAKA, T. B.; CAPPELLOZZA, A. Explorando a influência integrada do Estímulo Docente sobre a intenção de uso das bibliotecas virtuais por estudantes de cursos à distância e presenciais no Brasil. Investigación bibliotecológica, v. 32, n. 75, p. 19-45, 2018.

YOUNG, R. Knowledge management tools and techniques manual. Asian Productivity Organization, v. 98, 2010.

ZÁRRAGA, C.; BONACHE, J. Assessing the team environment for knowledge sharing: an empirical analysis. International Journal of Human Resource Management, v. 14, n. 7, p. 1227-1245, 2003.

ZOOM. About Zoom. Disponível em: https://zoom.us/about. Acesso em: 09 abr. 2020. 